\title{
Educação e Arquitetura: a educação patrimonial preservando o patrimônio arquitetônico
}

\author{
Educación y Arquitectura: educación patrimonial preservando \\ el patrimonio arquitectónico
}

Education and Architecture: heritage education preserving
Architectural heritage

Tarcisio Dorn de Oliveira

tarcisio_dorn@hotmail.com

Universidade Regional do Noroeste do Estado do Rio Grande do Sul, UNIJUÍ, Ijuí, RS

Jandha Telles Reis Vieira Müller

jandha_telles@hotmail.com

Universidade Regional do Noroeste do Estado do Rio Grande do Sul, UNIJUÍ, Ijuí, RS

Gabriel da Silva Wildner wildner.gabriel@gmail.com

Universidade Regional do Noroeste do Estado do Rio Grande do Sul, UNIJUÍ, Ijuí, RS

Caryl Eduardo Jovanovich Lopes

arqcaryl@gmail.com

Universidade Federal de Santa Maria, UFSM, Santa Maria, RS

Resumo: Nestes tempos onde a palavra preservação é tão vigente, principalmente no que se refere às questões ambientais e de sustentabilidade, o zelo pelo patrimônio arquitetônico ganha ênfase na consciência da sociedade, pois é ele que registra a forma da cidade no decorrer do tempo, bem como relembra e eterniza a história e os costumes do lugar. Nesta pesquisa, utilizou-se o estudo exploratório para explicitar a reflexão sobre o papel da educação patrimonial como possibilidade de (re)conhecimento do patrimônio arquitetônico local, ao mesmo tempo em que criam olhares que buscam e apreciam sua salvaguarda e manutenção. Evidencia-se o potencial aumento na identificação e pertencimento do cidadão ao local onde nasceu e/ ou habita.

Palavras-Chave: Materialidade no espaço, Legado, Salvaguarda.

Resumen: En tiempos en que la palabra preservación es tan vigente, principalmente en lo que se refiere a las cuestiones ambientales y de sostenibilidad, el celo por el patrimonio arquitectónico gana énfasis en la conciencia de la sociedad, pues es él quien describe la forma de la ciudad en el transcurso del tiempo, así como recuerda y eterniza la historia y las costumbres del lugar. En esta investigación se utilizó el estudio exploratorio para explicitar la reflexión sobre el papel de la educación patrimonial como posibilidad de los ciudadanos (re)conocer el patrimonio arquitectónico local, así como crear miradas que buscan y aprecian su salvaguardia y mantenimiento. 
Apuntarse el potencial aumento en la identificación y pertenencia del ciudadano al lugar donde nació y / o habita.

Palabras clave: Materialidad en espacio, Legado, Salvaguarda.

\begin{abstract}
In these times when the word preservation is so prevalent, especially regarding environmental and sustainability, zeal for architectural heritage has an emphasis on the consciousness of society, once it is who records the shape of the city over time, as well as it recalls and perpetuates the history and customs of the place. In this research, we performed an exploratory study aiming to explicit reflexions about the role of heritage education as a possibility for citizens (re)know the local architectural heritage besides creating looks that seek and appreciate its safeguard and maintenance. It points the increased potential in the citizens' identification and belonging feelings about the place where they were born and/or live in.
\end{abstract}

Key Words: Materiality in the space, Legacy, Safeguard.

\title{
CONSIDERAÇÕES INICIAIS
}

A preservação do patrimônio arquitetônico necessita de variados meios para despertar o olhar do cidadão às heranças deixadas a céu aberto por seus antepassados e para que estas sejam valorizadas e perpetuadas. Ao definir cultura como um fenômeno social produzido pelo homem, pode-se estreitamente considerar a arquitetura como uma produção social e, por consequência, cultural. O patrimônio arquitetônico se dá na coletividade e entende-se como respostas a movimentos que ocorrem em determinados momentos históricos ligando-se diretamente à memória e à construção da identidade e pertencimento de uma sociedade. Deste modo, conforme Callai (2005), partindo do fato de que percebemos o mundo ainda muito antes de ler a palavra, a principal questão a exercitar é a prática de fazer a leitura do mundo, fundamental para que todos nós, que vivemos em sociedade, possamos exercitar nossa cidadania. Ainda, Callai observa que ler o 'mundo da vida', ler o espaço é compreender que as paisagens visíveis são resultado da vida em sociedade, dos homens na busca da sua sobrevivência e da satisfação das suas necessidades.

Pesavento (2005) observa que a passagem do tempo modifica o espaço à medida que as práticas sociais do consumo e da apropriação do território alteram as formas do urbano e a função e uso do mesmo espaço, descaracterizando o passado da cidade. Nessa perspectiva, a autora salienta que todo traço do passado possui em si uma sucessão de temporalidades objetivas acumuladas, ou seja, as marcas da passagem dos anos e do uso e consumo pelos atores sociais que percorreram este espaço.

Nesse sentido, ao ler o espaço, Callai (2005) constata o desencadeamento do processo de conhecimento da realidade vivida cotidianamente ao construir-se conceitos, abstrações da realidade, a partir da compreensão da concretude, de onde se extraem elementos para 'pensar o mundo' ao construir nossa história e nosso espaço. Nesse caminho, ao confrontar lugares, tem início um processo de abstração que se assenta entre o real aparente, visível, perceptível e o concreto elaborado do que está sendo vivido. 
Nesse contexto, a educação patrimonial para Medeiros e Surya (2009) é um processo permanente e sistemático, centrada no patrimônio arquitetônico como fonte primária de conhecimento e enriquecimento individual e coletivo. Na visão de Faria e Woortmann (2009), a educação patrimonial busca transmitir aos sujeitos a noção da cultura como um processo social, participativo, não elitista (ao contrário da época de criação de muitas das instituições responsáveis pela gestão do patrimônio), e que o patrimônio é muito mais amplo do que edificações. Percebe-se assim que a educação patrimonial também engloba a formação cidadã ao trabalhar com a identidade e pertencimento dos cidadãos e a maior aproximação com seus bens e espaços culturais.

O patrimônio arquitetônico é a concretização física em um determinado tempo e espaço da dimensão simbólica das diversas formas de agir, sentir e viver dos grupos sociais em seus processos de identificação e vinculação comunitária. Assim, para Choay (2001), a preservação do patrimônio abrange diversos aspectos daquilo que é considerado histórico e no caso dos bens arquitetônicos essa discussão relaciona-se intimamente com uma de suas características intrínsecas, ou seja, o uso. A arquitetura é a única, entre as artes maiores, cujo uso faz parte de sua essência e mantém uma relação complexa com suas finalidades estética e simbólica.

Este ensaio destina-se a refletir o desenvolvimento da educação patrimonial como possibilidade dos cidadãos (re)conhecerem o patrimônio arquitetônico local.

\section{PERPETUANDO A MEMÓRIA DAS CIDADES ATRAVÉS DA PRESERVAÇÃO DO PATRIMÔNIO ARQUITETÔNICO}

A importância da preservação das materialidades (bens tangíveis e intangíveis) surge em meados do século XVIII em países europeus, visando criar uma identidade nacional específica a cada país. No Brasil, no entanto, esta preocupação aparece apenas no século XX, quando algumas cidades iniciaram um processo de modernização, principalmente no sudeste brasileiro, dando origem a uma crise de identidade nacional. Tanto na Europa como no Brasil, a preservação do patrimônio cultural iniciou-se, segundo Zanon, Magalhães e Branco (2009), com uma memória cristalizada, pertencendo a uma pequena parte da sociedade, em poucos lugares. Para Oliveira e Lopes (2018):

O patrimônio edificado pode ser pensado enquanto suporte do imaginário e da memória social de uma localidade, ou seja, os edifícios e áreas urbanas possuidoras de valor patrimonial podem ser tomados como um ponto de apoio da construção da memória, de valor e poder como um estímulo externo que ajuda a reativar e reavivar os traços arquitetônicos na formação sócio territorial. Nesse viés, a memória coletiva moldada pelo transpor do tempo não é mais de que um passeio através da história, revisitada e materializada no presente pela arquitetura, reforçando a ligação de identidade e pertencimento do ser humano em certo tempo e espaço (OLIVEIRA; LOPES, 2018, p. 14).

Nesse sentido, pode-se observar que a arquitetura é um processo ativo de conhecimento, relacionando-se com a memória, a identidade e o pertencimento. A história, a memória, a identidade e o pertencimento podem ser entendidos por meio da arquitetura, 
possibilitando um conhecimento crítico e uma apropriação consciente dos bens patrimoniais por parte dos sujeitos. Grande parte da memória urbana da cidade pode ser visualizada na arquitetura, transmitindo às novas gerações os episódios históricos que neles tiveram lugar.

Pesavento (2005) observa que habitar uma cidade, viver em espaço urbano é, forçosamente, dotá-lo de condições para o exercício da vida para além do tempo do agora, do cotidiano da existência, do presente da cidade. É um elemento no espaço onde se reabilita o passado da urbe, material e imaterial, para que nela os sujeitos se reconheçam e identifiquem, ancorando suas referências de memória e história. A autora ainda adverte que o presente das cidades é também aquele tempo onde se gesta o futuro, se articulam planos e projetos de renovação do espaço, em antecipação por vezes utópica, de um outro tempo ainda a realizar-se. Enfim, onde uma cidade interpreta/inventa seu passado e cria o seu futuro para explicar seu presente.

A preservação do patrimônio, por isso, não deve estar alinhada à ideia de congelamento, mas na necessidade de (re)apropriação dos espaços, bem como na criação de novos, levando em consideração seus usos, olhares e fazeres sociais. Zanon, Magalhães e Branco (2009) observam que, apesar da necessidade de novos olhares e possibilidades para estes espaços ou edificações, o processo não é tarefa fácil, visto que se trabalha com espaços de expressão identitária, juntamente com as contradições e conflitos decorrentes de cada época. Para Oliveira e Lopes (2018):

Preservar os prédios antigos não é só guardar recordações dos velhos tempos, é possibilitar que outras gerações possam estudá-los, observá-los e tirar suas conclusões sobre a evolução que ali se sucedeu, além de se encantarem com suas formas e ter uma prova concreta de que aquilo que lhes falam realmente existiu. A construção da memória social urbana implica na referência ao que não foi presenciado, onde representa processos e estruturas sociais que já se transformam (OLIVEIRA; LOPES, 2018, p. 14-15).

A memória, seja ela individual ou coletiva, pode e deve ser associada ao patrimônio arquitetônico, identificando as tradições e as construções de cada indivíduo ou comunidade, formando e solidificando a herança cultural local. A arquitetura é capaz de instigar e desenvolver a percepção e a imaginação, e propicia uma reflexão crítica ao permitir analisar o ambiente construído e percebido de maneira a desenvolver nos sujeitos uma visão crítica e reflexiva para o ato de sua preservação.

A relevância de preservar o patrimônio está no ato de conservar a memória e a tradição do povo por meio do seu patrimônio edificado. A preservação da arquitetura, conforme Tomaz (2010), justifica-se porque a vida de uma comunidade relaciona-se ao seu passado, à sua vivência. Consequentemente, relaciona-se às transformações ocorridas na sua história de modo que a preservação objetiva servirá como lugares da memória, ou seja, um local de referência dos acontecimentos da comunidade, refletida nesses espaços. Barretto (2000) aponta que:

Preservar significa proteger, resguardar, evitar que alguma coisa seja atingida por alguma outra que lhe possa ocasionar dano. Conservar significa manter, guardar para 
que haja uma permanência no tempo. Desde que guardar é diferente de resguardar, preservar o patrimônio implica mantê-lo estático e intocado, ao passo que conservar implica integrá-lo no dinamismo do processo cultural (BARRETTO, 2000, p. 15).

As expressões culturais de uma cidade são fruto de todos os saberes e de todas as memórias das experiências humanas. Nessa perspectiva, a arquitetura contempla e caracteriza-se por uma pluralidade de valores (econômicos, sociais, técnicos, funcionais, artísticos, espaciais e decorativos). Do mesmo modo que se produz as cidades, também os sujeitos se produzem coletivamente, posto que a figura da cidade que se quer está vinculada aos projetos sobre as possibilidades humanas, sobre quem queremos vir a ser ou, talvez, de modo mais pertinente, em quem não queremos nos transformar.

Segundo Castriota (2009), o conceito de patrimônio arquitetônico, ao se afastar da noção reificada de monumento, incorpora a ideia da dinâmica da cultura e do ambiente construído. Por outro lado, nota-se que por meio da mediação de ideias, como a de sustentabilidade e de qualidade ambiental, há a necessidade de se pensar conjuntamente as chamadas áreas históricas e o restante do tecido urbano e do território.

Para preservar a memória urbana e o patrimônio arquitetônico é necessário conhecer e compreender o significado do que é produzido pela sociedade. Gazzóla (2009) salienta que a necessidade de preservar a memória coletiva ganha, a cada dia, espaço nas mais variadas áreas. Isso porque grande parte dos empreendimentos que envolvem um espaço territorial, o qual compreende o patrimônio arquitetônico, histórico, artístico, cultural ou natural, possui um compromisso social - o de salvaguardar essas evidências por meio de leis, normativas, projetos ou outras iniciativas. Para Murta e Albano (2002):

Desenvolver a preservação e a interpretação de nossos bens culturais, traduzindo seu sentido para quem os visita. Mais que informar, a interpretação tem como objetivo convencer as pessoas do valor de seu patrimônio, encorajando-as a conservá-lo. Esta é a sua essência (MURTA; ALBANO, 2002, p. 10).

A presença da materialidade no espaço reforça um sentimento de segurança, estabilidade, identidade e pertencimento imprescindível à memória coletiva dos grupos sociais. Logo, sua preservação torna-se fundante, haja vista, que o patrimônio arquitetônico são bens materiais presentes no ambiente construído, que contam a história de um povo e sua relação com o meio - legado herdado do passado e transmitido às novas gerações. Dessa forma, possuem a capacidade de estimular a memória das pessoas historicamente vinculadas a ele, e por isso deveria ser alvo de estratégias visando à sua promoção e preservação. A preocupação em protegê-lo possibilitou a criação de várias normativas, comissões e conferências para o estabelecimento de critérios para sua proteção e conservação.

Para Choay (2001) a preservação do patrimônio abrange diversos aspectos daquilo que é considerado monumento histórico, onde no caso dos bens arquitetônicos a discussão relaciona-se intimamente ao seu uso. Dessa forma, o patrimônio arquitetônico constitui a construção física, determinada no tempo e espaço, com uma dimensão simbólica advinda das diversas formas de agir, sentir e viver dos grupos sociais a partir do que as comunidades estabeleceram como processos de identificação e vinculação comunitária. 


\section{PROMOVENDO A EDUCAÇÃO PATRIMONIAL ATRAVÉS DO PATRIMÔNIO ARQUITETÔNICO}

É de grande relevância saber reconhecer os prédios arquitetônicos que representam a história e os acontecimentos de cada época, por meio de demarcação (com placas de identificação), para que a população os identifiquem. Preservá-los como marco da cultura de um determinado tempo e espaço é remontar e contar a história da cidade e sua população. Nesse cenário, Figueiredo (2013) diz que pensar a cidade nesse contexto equivale a identificar as nuances do comportamento humano, na medida em que ela se constitui em materialidade, em seus construtos patrimoniais e imaterialidade, resultante dos símbolos e significados conferidos pelos diferentes atores sociais ao longo dos processos históricos. Segundo Martins (2006):

O território em que vivemos é mais que um simples conjunto de objetos, mediante os quais trabalhamos, circulamos, moramos, mas também um dado simbólico. A linguagem regional faz parte desse mundo de símbolos, e ajuda a criar essa amálgama, sem o qual não se pode falar de territorialidade. Esta não provém do simples fato de viver num lugar, mas da comunhão que com ele mantemos (MARTINS, 2006, p. 39).

A preservação do patrimônio e o resgate da memória são constituídos de impressões, experiências e significados que nos dão a dimensão de sentido no mundo. Esses bens e/ ou espaços de memória representam a força do lugar, possibilitando a noção de despertar sentimentos de afetividade e pertencimento aos sujeitos da cidade. A arquitetura salva a humanidade do esquecimento oferecendo sentido de continuidade da vida - uma fuga da ação do tempo pessoal e o mergulho em um tempo coletivo. As cidades são consideradas monumentos pela significação da arquitetura patrimonial, elo importante na história evolutiva do desenvolvimento urbano, econômico, social, religioso e filosófico com a constituição e formação humana e cidadã.

Para Grunberg (2000) não há sentido na guarda e preservação de um bem cultural se o próprio objeto em questão não despertar no sujeito que o observa e estuda uma experiência concreta de evocação e compreensão do passado. É nessa proposta de utilizar o bem cultural como recurso educacional, aplicando-se uma metodologia de trabalho, que se encontra a essência da educação patrimonial. Ou seja, o patrimônio arquitetônico, como processo de aprendizagem, deve levar o sujeito a uma experiência que contemple a percepção/observação, motivação, memória e emoção.

A preservação dos espaços da cidade, bem como suas edificações históricas, permite que a memória de um povo seja perpetuada, renovada e (re) significada diariamente (TOMAZ, 2010). Esta singularidade do espaço e do tempo passado é definida por Milton Santos (1986), de forma quase poética:

O passado passou, e só o presente é real, mas a atualidade do espaço tem isto de singular: ela é formada de momentos que foram estando agora cristalizados como objetos geográficos atuais; essas formas-objetos, tempo passado, são igualmente tempo presente enquanto formas que abrigam uma essência, dada pelo fracionamento da 
sociedade total. Por isso, o momento passado está como morto "tempo", não, porém como "espaço"; o momento passado já não é, nem voltará a ser, mas sua objetivação não equivale totalmente o passado, uma vez que está sempre aqui e participa da vida atual como forma indispensável à realização social (SANTOS, 1986, p. 10).

Ensinar tendo como fonte primária o patrimônio arquitetônico viabiliza a formação de indivíduos capazes de conhecer a sua própria história cultural. Cerqueira (2005) observa que a educação valoriza cada vez mais seu papel como promotora de cidadania, pois a escola não somente informa conhecimentos que futuramente comporão a base da formação profissional, mas sobretudo forma cidadãos. Utilizar o patrimônio arquitetônico local como ponto de partida no processo de ensino e aprendizagem, conforme Santos (2007), contribui para a formação da cidadania ao promover o fortalecimento da identidade cultural, capacitando e instigando a comunidade a (re)descobrir e perceber os valores e particularidades da sua história por meio da aplicação de metodologias de educação patrimonial. Oliveira e Lopes (2018) afirmam que:

A maior parte desta história está apresentada em seus prédios, cuja suas fachadas preservam em seus diversos estilos a linha do tempo do povo que ali habita. Nesse sentido, a arquitetura vista como monumento e carregada de monumentalidade, valor e poder contribui significativamente para o transporte da memória urbana de uma geração a outra, onde tais testemunhos edificados estão na memória coletiva constituindo uma característica peculiar de cada espaço urbano, onde somente os moradores conseguem ver esta luz e perceber a relevância de valorizar a arquitetura local (OLIVEIRA; LOPES, 2018, p. 15).

O patrimônio arquitetônico é a construção física em um determinado tempo e espaço, sendo a dimensão simbólica das diversas formas de agir, sentir e viver dos grupos sociais, quando as comunidades estabelecem processos de identificação e vinculação comunitária em relação a uma dada cultura. Logo, Dimenstein (2017) observa que através de ações voltadas à preservação e compreensão do patrimônio cultural, a educação patrimonial torna-se um veículo de aproximação, conhecimento, integração e aprendizagem de crianças, jovens, adultos e idosos, objetivando a que os mesmos (re)conheçam, (re)valorizem e se (re)apropriem de toda uma herança cultural a eles pertencente, proporcionando aos mesmos uma postura mais crítica e atuante na (re)construção de sua identidade e cidadania. Identidade essa que, cada vez mais, urge por uma atenção especial dos diversos setores da nossa sociedade.

Trabalhar questões referentes ao patrimônio arquitetônico é oferecer aos cidadãos subsídios para a construção do conhecimento, da valorização e da preservação desses bens culturais, sejam eles materiais, imateriais, naturais ou construídos. Para Cerqueira et al. (2008) e Teixeira (2008), um dos principais motivadores da educação patrimonial seria, através da abordagem inclusiva, o fomento à autoestima das comunidades locais, estimulando o conhecimento e valorização de seu patrimônio, memória e identidade cultural.

A educação patrimonial vincula-se com a experimentação e vivência do meio, com a leitura de mundo onde se insere o cidadão (SABALLA, 2007). A partir disso, possibilita-se a 
que o indivíduo se sinta pertencente e usuário do seu direito à memória - enfim, de cidadania. Horta, Grunberg e Monteiro (1999) reforçam que o processo ativo de conhecimento, de apropriação e valorização da herança cultural, por meio da educação patrimonial, além de possibilitar o melhor usufruto destes bens e a produção de novos conhecimentos, permite maior consciência de preservação patrimonial e fortalece os sentimentos de identidade e cidadania. Corroborando, Dimenstein (2017) observa que:

[...] o patrimônio entendido como todos os bens de natureza material portadores de referência à identidade, à ação e à memória dos diferentes grupos formadores da nossa realidade, é um promissor instrumento pedagógico ao exercício da cidadania uma das finalidades do programa educacional. Não é por outra razão a necessidade de preservar o espaço, enquanto expressão de memória coletiva, de uma identidade compartilhada. Deve-se tratar a cidade como um tecido vivo, um organismo histórico em desenvolvimento e, assim, adotar medidas de conservação do patrimônio como continuidade de valores culturais, no âmbito de um processo de mudança, de maneira que a personalidade cultural seja preservada (DIMENSTEIN, 2017, p. 23).

A educação patrimonial pode ser desenvolvida no ambiente formal e não formal de ensino (comunidades, associações de bairro, museus, parques, etc.) e também se adequar a qualquer tipologia de patrimônio, ou seja, qualquer evidência material ou manifestação da cultura pode ser fonte para o desenvolvimento da educação patrimonial. Souza (2008) salienta que, além de um importante documento, o patrimônio cultural edificado tem sua relevância no tocante ao vínculo direto com o passado, muito perceptível para os alunos, sobretudo dada à proximidade tátil, haja visto serem fragmentos da história ainda palpáveis e perceptíveis num simples caminhar descompromissado pelas ruas das cidades.

A educação patrimonial leva em conta territórios e lugares como espaços educativos. Por isso, para Dimenstein (2017), o patrimônio cultural de uma cidade não se restringe apenas aos bens edificados, mas se expande para além dos muros de um espaço físico ou espaços territoriais como documento vivo, passível de leitura e interpretação por meio de múltiplas estratégias. Ao interligar os espaços tradicionais de aprendizagem aos equipamentos públicos, como centros comunitários e bibliotecas públicas, praças e parques, teatros e cinemas, a educação patrimonial se potencializa, tornando-se também mais efetiva quando integrada às demais dimensões da vida e articulada às práticas cotidianas e marcos de referências identitárias ou culturais de seus usuários.

A memória de uma sociedade constitui seu próprio futuro, uma vez que constrói, ao longo do tempo, referenciais sociais, políticas e culturais. No espaço onde se localizam as cidades, permitem, de forma mais durável, ainda que em ruínas, o registro de seus antepassados, haja vista, que o espaço é armazenador de histórias e leituras vividas no tempo passado, e percebidas no tempo presente. Para Oliveira e Callai (2017), retomando as edificações presentes nesse espaço/cidade/tempo, estas compõem fortemente o patrimônio cultural ao dizer respeito às maneiras de o sujeito existir, pensar e se expressar, bem como as manifestações simbólicas dos seus saberes, práticas artísticas, sistema de valores e tradição. Canani (2005) afirma que a arquitetura vista como patrimônio está relacionada 
a um bem tão valioso que justifica sua herança e preservação, por nela estar incutida a memória e a identidade de quem o deixa e de quem o herda. Nessa perspectiva, Oliveira e Callai (2017) ainda reforçam:

A arquitetura possui a capacidade de estimular a memória das pessoas, e por isso, é alvo de estratégias que visam a sua promoção e preservação, onde a preocupação em protegê-lo começou no início do século XX, sendo criadas a partir daí várias normativas, comissões e conferências para estabelecer critérios para proteger e conservar o patrimônio. Observa-se a importância de entrelaçar situações de ensino e aprendizagem com o que se denomina de preservação da arquitetura, onde a noção de preservação do patrimônio surge junto a movimentos sociais que buscam a autonomia e a valorização da cultura local e global (OLIVEIRA; CALLAI, 2017, p. 147).

Ao transportar a arquitetura para a realidade dos sujeitos, promovendo uma maior interação entre arquitetura, história, memória, identidade e pertencimento, a educação pela arquitetura proporciona ao sujeito fazer a leitura do mundo que o rodeia, levando-o à compreensão do universo sociocultural e da trajetória histórico-temporal em que está inserido. Para oportunizar e facilitar o processo, a educação patrimonial está baseada em um método ativo, com o pressuposto permanente de ensinar crianças e adultos a aprender a conhecer o seu patrimônio local, compartilhando esses conhecimentos e saberes.

Diante disso, desenvolver a relação entre o contato direto com o patrimônio arquitetônico, contextualizando e percebendo os lugares de memória da comunidade presentes, contribui para que o indivíduo possa fazer associações entre realidade passada e imediata, para a percepção de limites geográficos de sua cidade e sua importância (HORTA; GRUNBERG; MONTEIRO, 1999). Referente a esse processo, Barreto et al. (2008, p. 39) afirmam que "a educação patrimonial consiste em provocar situações de aprendizado sobre o processo cultural, seus produtos e manifestações, despertando nos cidadãos o interesse em resolver questões significativas para sua própria vida, pessoal e coletiva".

A educação patrimonial consiste, portanto, em provocar situações de aprendizado sobre o processo cultural e, a partir de suas manifestações, despertar interesse em questões significativas para a vida pessoal e coletiva. A ligação entre educação e preservação do patrimônio seria então fundamental para a formação do indivíduo, pois o processo educacional, centrado na arquitetura é um instrumento de gestão e alfabetização cultural, capacitando os sujeitos para a leitura e compreensão do universo sociocultural em que estão inseridos.

\section{CONSIDERAÇÕES FINAIS}

A degradação da arquitetura patrimonial é uma questão preocupante nas mais diversas possibilidades de análise. Mesmo sendo amparada por uma ampla legislação para sua preservação, na prática se observam falhas e morosidade no seu cumprimento, acarretando a perda de bens patrimoniais em função da ineficiência de fiscalização. A valorização do patrimônio arquitetônico e sua inserção no cotidiano dos cidadãos permite 
que tais edificações sejam percebidas, constituindo-se como parte integrante do passado e da história local. A identidade e o pertencimento de uma comunidade se efetivam ao passo que o campo afetivo se relaciona com o espaço físico cotidiano, isto é, a sociedade que experiência em seu cotidiano a presença do patrimônio tem sua autoestima e seu pertencimento consolidados.

O patrimônio arquitetônico representa a memória coletiva, agregação do contexto social, político e econômico de determinada época, e cabe à educação patrimonial possibilitar formas de análise e estudo para compreensão da história em sua totalidade. É perceptível que, diante do processo de modernização das cidades, observa-se um profundo desconhecimento e desvalorização de seu patrimônio. Investir na preservação e salvaguarda da arquitetura através da educação é de extrema importância, pois possibilita aos sujeitos uma reflexão no que tange a questões referentes à promoção e vivência da cidadania, reforçando os laços com a identidade e pertencimento ao local.

É salutar compreender a educação patrimonial como metodologia de preservação, pois ela possibilita que o indivíduo faça a leitura do mundo que o rodeia, valorizando sua cultura material resultante da relação entre os indivíduos e seu ambiente, onde, por meio do patrimônio, é possível conscientizar os sujeitos a conhecer, compreender e preservar a própria história. A consciência de preservar contribui muito para que as próximas gerações possam desfrutar dessas edificações como símbolos do passado, podendo compreender o desenvolvimento dos fluxos desse espaço e reconhecer o sentido de pertencimento e resgate da memória da cidade. Nessa lógica, as políticas de preservação do patrimônio devem transformarem-se em peças fundamentais e estratégicas identificadas como verdadeiros instrumentos de ordenamento da cidade.

A educação patrimonial possibilita a interpretação dos bens culturais, sendo um instrumento importante para valorizar e preservar o patrimônio, pois utiliza-se dos lugares e suportes da memória no processo educativo, desenvolvendo a sensibilidade dos educandos e dos cidadãos para a importância da preservação da arquitetura. A educação patrimonial possui papel importante para tais reflexões e questionamentos, propiciando a aproximação mais efetiva da comunidade aos seus bens e espaços culturais, mesmo que estes, em um primeiro momento, representem parcelas pequenas da sociedade, selecionados geralmente pelas classes mais abastadas e detentoras do poder.

A educação patrimonial é instrumento primordial para a sustentabilidade da arquitetura e da memória urbana de uma cidade, pois por meio dela é possível (re)conhecer o patrimônio como algo que constitui uma parcela do processo de formação da cultura dos cidadãos e, a partir daí, surge a responsabilidade sobre o bem e a vontade de querer protegê-lo. A criticidade do trabalho em educação patrimonial está pautada, a partir do momento em que se começa a investigar a arquitetura presente, nas referências simbólicas e afetivas em relação ao espaço vivido, constituindo a imagem e identidade da cidade. 


\section{REFERÊNCIAS}

BARRETO, E. A. et al. Patrimônio cultural e educação: artigos e resultados. Goiânia, 2008.

BARRETTO, M. Turismo e legado cultural: as possibilidades do planejamento. Campinas: Papirus, 2000.

CALLAI, H.C. Aprendendo a ler o mundo: a geografia nos anos iniciais do ensino fundamental. Caderno Cedes, v. 25, n. 66, p. 227-247, 2005.

CANANI, A.S.K.B. Herança, sacralidade e poder: sobre as diferentes categorias do patrimônio histórico e cultural no Brasil. Horiz. antropol., v.11, n.23, p. 163-175, 2005.

CASTRIOTA, L.B. Paisagem Cultural e sustentabilidade. Belo Horizonte: Ed. UFMG, 2009.

CERQUEIRA, F.V. Patrimônio Cultural, Escola, Cidadania e Desenvolvimento Sustentável. Diálogos, v. 9, n. 1, p.91-109, nov. 2005.

CERQUEIRA, F.V; BENDJOUYA, G; SANTOS, D.O.M. dos; MELO, A.D. de. Educação Patrimonial: perspectivas multidisciplinares. Pelotas: Ed. UFPel, 2008.

CHOAY, F. A alegoria do patrimônio. São Paulo: UNESP, 2001.

DIMENSTEIN, D. Educação patrimonial, memória e cidadania: a experiência dos professores de história da rede municipal de Jaboatão dos Guararapes - PE. Salvador, 2017. 44 f. Monografia (Curso de Formação de Gestores Culturais dos Estados do Nordeste) - Universidade Federal da Bahia, UFBA.

FARIA, N.D.M. de; WOORTMANN, E.F. A Educação Patrimonial como elemento de socialização para jovens em situação de risco. Revista Hospitalidade, v. 6, n. 2, p. 49-72, jun.- dez. 2009.

FIGUEIREDO, L.C. Perspectivas de análise geográfica do patrimônio cultural: algumas reflexões. Geografia Ensino \& Pesquisa, v. 17, n. 1, p. 55-70, jan. 2013.

GAZZÓLA, L. Educação patrimonial: teoria e prática. In: CONGRESSO NACIONAL DE EDUCAÇÃO, 9 , 2009, Curitiba. Anais... p. 1445-1457.

GRUNBERG, E. Educação patrimonial: utilização dos bens culturais como recursos educacionais. Cadernos do CEOM, v.14, n.12, p.159-180, jun. 2000.

HORTA, M.L.P.; GRUNBERG, E.; MONTEIRO, A.Q. Guia Básico de Educação Patrimonial. Brasília: IPHAN/Museu Imperial, 1999.

MEDEIROS, M.C. de; SURYA, L. A importância da educação patrimonial para a preservação do patrimônio. In: SIMPÓSIO NACIONAL DE HISTÓRIA. 25, 2009, Fortaleza. Anais ... Disponível em: https:/ /anpuh. org.br/uploads/anais-simposios/pdf/2019-01/1548772007_78c4449e3d9ea65b86d531e61c3d4119.pdf Acesso em: 26 ago. 2019.

MARTINS, C. (Org.). Patrimônio cultural: da memória ao sentido do lugar. São Paulo: Roca, 2006.

MURTA, S.M.; ALBANO, C. (org.). Interpretar o patrimônio: um exercício do olhar. Belo Horizonte: Ed. UFMG, 2002.

OLIVEIRA, T.D. de; CALLAI, H.C. Compreender a cidade e a arquitetura através da educação patrimonial. Revista Di@logus, v. 6, n. 3, p. 141-149, set. 2017.

; LOPES, C.E.J. Monumento, monumentalidade, valor e poder: interações com a memória e preservação arquitetônica. METAgraphias: letra JK de JK de utopias políticas possíveis, v.3, n.3, p. 1-17, 2018.

PESAVENTO, S.J. Cidade, Espaço e Tempo: reflexões sobre a memória e o patrimônio urbano. Cadernos do LEPAARQ, v. 2, n. 4, p. 9-17, ago. 2005.

SEVERO, F. Espaço arquitetônico e espaço turístico: memória, história e simulacros. In: SEMINÁRIO DE PESQUISA EM TURISMO NO MERCOSUL, I2, 2004, Caxias do Sul. Anais... p. 1-14.

SABALLA, V.A. Educação Patrimonial: Lugares de Memória. Revista Mouseion, v.1, p. 1-3, jul. 2007.

SANTOS, M.S.S. Educação e Patrimônio: uma construção da Identidade. Fórum Identidades, v. 2, n. 1, p. 49-60, jul. 2007. 
SANTOS, Milton. Pensando o espaço do homem. 2.ed. São Paulo: HUCITEC, 1986.

SOUZA, V.V. Espichar e escorar: Modernização e preservação na Terra do Bode (Batalha-PI). O que fazer? In: CONGRESSO INTERNACIONAL DE HISTÓRIA E PATRIMÔNIO CULTURAL, 1, 2008, Teresina. Anais... Disponível em: http:/ / paginadebatalha.com.br/arquivos/File/artigo\%20patrimonio\%20cultural. pdf Acesso em: 26 ago. 2019.

TEIXEIRA, C.A.R. A educação patrimonial no ensino de história. Biblos, v. 22, n. 1, p. 199-211, 2008.

TOMAZ, P.C. A Preservação do Patrimônio Cultural e sua Trajetória no Brasil. Revista Fênix, v. 7, n. 2, p. 1-12, 2010.

ZANON, E.R.; MAGALHÃES, L.H.; BRANCO, P.M.C. Educação Patrimonial: da teoria à prática. Londrina: UNIFIL, 2009.

Data de submissão: 24/ jan./ 2019

Data de aceite: 27/ ago./ 2019 